\title{
A INCLUSÃO DOS ESTUDANTES SURDOS NAS AULAS DE MATEMÁTICA
}

Denner Dias Barros, Klaus Schlünzen Júnior, Danielle Aparecida do Nascimento dos Santos, Ana Virgínia Isiano Lima, Ana Mayra Samuel da Silva

Universidade Estadual Paulista - UNESP, Licenciatura em Matemática, Presidente Prudente, SP. E-mail: dennerdias12@gmail.com. Agência de fomento: FAPESP

\section{RESUMO}

O ensino de Matemática, especialmente relacionado à resolução de problemas para os estudantes surdos ainda é um dilema para o sistema educacional, uma vez que existem barreiras linguísticas que trazem implicações na maneira como o professor media o conhecimento matemático em sala de aula, voltado à compreensão desses estudantes. $O$ presente trabalho apresenta apontamentos sobre a utilização da resolução de problemas no ensino de conceitos matemáticos para estudantes surdos em uma perspectiva inclusiva. Mediante a realização de um estudo de caso, foi possível verificar como a resolução de problemas pode ser desenvolvida em um trabalho colaborativo e em propostas diferenciadas nas aulas de Matemática com a presença de uma estudante surda.

Palavras-chave: Ensino de Matemática, Resolução de Problemas, Estudantes Surdos, Educação Especial na perspectiva da Educação Inclusiva, Trabalho Colaborativo.

\section{INCLUSION OF DEAF STUDENTS IN THE CLASSES OF MATHEMATICS}

\begin{abstract}
The teaching of mathematics, especially related to solving problems for deaf students is still a dilemma for teachers of mathematics, caused by language barriers and how the teacher mediates the mathematical knowledge in the classroom. This paper presents notes on the use of problem solving in math concepts for teaching deaf students in an inclusive perspective. By conducting a case study, it found as problem solving is used in school and develop differentiated proposals for work with problem solving in mathematics classes, with a deaf student.
\end{abstract}

Keywords: Mathematics Teaching, Problem Solving, Deaf Students, Special Education from the perspective of Inclusive Education, Collaborative Work. 


\section{INTRODUÇÃO}

A inclusão das pessoas surdas em uma comunidade majoritariamente ouvinte encontrou e ainda encontra empecilhos que apenas conseguem ser superados ou amenizados mediante muita luta e com a realização de mobilizações viabilizando a busca da desmistificação de características pejorativas atribuídas a essas pessoas, como o fato de que essas pessoas não ouvirem influencia diretamente na capacidade de raciocínio. Neste processo, “[...] as pessoas surdas, ao longo do caminho, enfrentam descrédito, preconceito, piedade e loucura" (SALLES, 2004, p.50).

No Brasil, as Diretrizes Nacionais para a Educação Especial na Educação Básica (Resolução do Conselho Nacional de Educação/Câmara de Educação Básica no 2/2001), buscando instituir uma legislação que evidencia as concepções da Educação Especial em uma perspectiva inclusiva, determinou que os sistemas de ensino tem o dever de matricular todos os estudantes, cabendo às escolas organizarem-se para o atendimento aos Estudantes Público-Alvo da Educação Especial $(E P A E E)^{1}$ e garantir as condições necessárias para oferecer à esses estudantes um aprendizado de qualidade.

Com a Lei 10.436/02, a Língua Brasileira de Sinais (Libras) passou a ser reconhecida como meio legal de comunicação e expressão da comunidade surda brasileira. E através de parágrafo único sancionou que se entende como Libras a forma de comunicação e expressão, em que o sistema linguístico de natureza visual-motora, com estrutura gramatical própria, constitui um sistema linguístico de transmissão de ideias e fatos, oriundos de comunidades de pessoas surdas do Brasil.

O decreto no 5626/05 colabora com a lei 10.436/02, regulamentando o acesso dos estudantes surdos à escola comum, dispondo sobre a instituição da Libras como disciplina curricular obrigatória nos cursos de formação de professores e fonoaudiologia e a organização escolar para um ensino bilíngue para os surdos, sendo a Língua Portuguesa compreendida como segunda língua para os estudantes surdos.

Através da Resolução CNE/CEB no 4/2009, o Conselho Nacional de Educação estabelece as Diretrizes Operacionais para o Atendimento Educacional Especializado (AEE) na Educação Básica, no qual, o Art. 5 garante que a realização AEE.

O AEE deve ser realizado prioritariamente no contra turno da escolarização nas Salas de Recursos Multifuncionais (SRM) da própria escola, em outra instituição de ensino regular ou em centro de atendimento educacional especializado. Portanto, essa modalidade de ensino não é substitutiva às classes comuns, mas complementar.

\footnotetext{
${ }^{1}$ Pessoas com deficiências físicas, intelectuais, sensoriais e múltiplas; transtornos globais do desenvolvimento e altas habilidades/superdotação. 
As SRM são ambientes dotados de equipamentos pedagógicos e tecnológicos, mobiliários e materiais didáticos voltados para a oferta do AEE. A SRM é caracterizada como um ambiente para a realização do AEE para os EPAEE podendo ser temporário ou permanente. Objetivando o desenvolvimento do currículo e a participação efetiva na vida escolar dos EPAEE, devem ser utilizados os materiais e equipamentos por meio do desenvolvimento de estratégias de abordagem centradas sempre no apoio à educação realizada na classe comum.

Em se tratando do contexto do Estado de São Paulo, a Resolução SE 61 de 11 de novembro de 2014 traz apontamentos sobre a escolarização dos Estudantes Público-Alvo da Educação Especial (EPAEE) no seu sistema público. Essa resolução reafirma o direto do estudante a uma educação de qualidade, igualitária e centrada no respeito à diversidade. Além de ressaltar a importância de garantir o Atendimento Pedagógico Especializado $(\mathrm{APE})^{2}$ para esses estudantes, com condições de acesso e apoio à aprendizagem.

Diferentemente das SRM que atendem todos os EPAEE, as Salas de Recursos (SR) do Estado de São Paulo são organizadas por tipos de deficiência, transtornos globais do desenvolvimento ou altas habilidades/superdotação. Ou seja, existem salas voltadas para o atendimento de estudantes com Deficiência Visual, outras para o atendimento de estudantes com Deficiência Intelectual, entre outras.

Partindo desse cenário educacional, um importante desafio para a educação brasileira é a construção de uma escola das diferenças e para as diferenças, que proporcione para as estudantes condições de acesso e permanência à escola.

A Matemática é uma disciplina considerada por muitos estudantes como difícil e desinteressante. Esse fato pode acarretar na falta de estímulos para que os estudantes dediquemse ao estudo da Matemática na Educação Básica. Na busca da solução desses entraves, Moran Costas (2009, p.10) afirma que deve-se

[...] tornar a escola um espaço vivo, agradável, estimulante, com professores mais bem remunerados e preparados; com currículos mais ligados à vida dos alunos; com metodologias mais participativas que tornem os alunos pesquisadores, ativos; com aulas mais centradas em projetos do que em conteúdos prontos [...].

O professor de Matemática que trabalha em uma perspectiva inclusiva, para Gil (2007, pg.53), deve estimular o desenvolvimento da criatividade, a receptividade para as mudanças e adaptar as habilidades e conhecimentos nas mais variadas situações. Para que assim, seus

\footnotetext{
${ }^{2}$ O Atendimento Pedagógico Especializado (APE) do estado de São Paulo trabalha na mesma perspectiva do AEE, apenas possuindo uma organização um pouco diferenciada. 
estudantes alcancem autonomia e criticidade e, dessa forma, consigam identificar problemas e encontrar caminhos para resolvê-los. Uma das propostas é que os professores trabalhem com seus estudantes a resolução de problemas.

O objetivo desse artigo é apresentar a pesquisa "O Ensino de Conceitos Matemáticos para Estudantes Surdos em uma Perspectiva Inclusiva" financiada pela Fundação de Amparo a Pesquisa do Estado de São Paulo (FAPESP), cujo objetivo foi verificar de que forma o professor da sala de recursos e o professor de Matemática da classe comum podem trabalhar em conjunto, em uma perspectiva de trabalho colaborativo, para favorecer a inclusão de uma estudante surda, nas aulas de Matemática, em uma escola pública do Estado de São Paulo, vinculada à Diretoria de Ensino de Presidente Prudente/SP.

\section{METODOLOGIA}

A pesquisa pode ser considerada de caráter qualitativo, dado que, esse tipo de estudo, segundo Lüdke e André (1986, apud Bogdan e Biklen 1982, pg.13): “Envolve a obtenção de dados descritivos, obtidos no contato direto do pesquisador com a situação estudada, enfatiza mais o processo do que o produto e se preocupa em retratar a perspectiva dos participantes".

O trabalho foi realizado em parceria com duas professoras, uma professora de Matemática e uma professora do AEE que trabalham com uma estudante surda em comum. Dessa forma, se trata de uma pesquisa qualitativa, do tipo colaborativa. De acordo com Capellini (2004, pg. 104), a pesquisa colaborativa pode ser entendida como um modelo de pesquisa em que os pesquisadores abandonam papéis tradicionais de detentores do saber, e os pesquisados não são meros objetos de análise e de compreensão, mas se tornam colaboradores na organização da pesquisa e na construção de novas realidades.

A coleta de dados em campo foi realizada na Escola Estadual João da Silva ${ }^{3}$ do município de Presidente Prudente - SP. A escola atende estudantes do 6으 ano 9을 ano do Ensino Fundamental e estudantes do 10 ano 3 ano do Ensino Médio, além de possuir duas Salas de Recursos. Serão retratadas a seguir características importantes da escola e da SR em que a pesquisa foi desenvolvida.

\section{RESULTADOS}

Atualmente a Escola Estadual Professor João da Silva conta com dois períodos (matutino e vespertino) com 398 estudantes matriculados no Ensino Fundamental, 305 estudantes

\footnotetext{
${ }^{3}$ Este é um nome fictício para a escola que constitui o campo da pesquisa, a fim de preservar os participantes. 
frequentando o Ensino Médio e 24 estudantes matriculados entre as duas salas de recursos, uma especializada para o atendimento de estudantes com Deficiência Auditiva (DA) e a outra para estudantes com Deficiência Visual (DV).

A estudante, sujeito da pesquisa, denominada $A^{4}$ tem 18 anos e é Surda. Estuda na Escola Estadual João da Silva no 3o no B - Ensino Médio, sala com 39 estudantes, onde A é a única estudante surda. Estudante A conta com o acompanhamento de uma professora interlocutora de Libras durante todas as aulas.

A professora de Matemática da turma é a professora $\mathrm{R}$, graduada em Licenciatura em Matemática pela Universidade Estadual Paulista - “Júlio de Mesquita Filho" (Unesp). Lecionou na E.E. João Silva por 2 meses no ano de 2012, no qual teve o primeiro contato como professora da estudante A, e voltou a ministrar aulas de Matemática na escola em 2015.

A Estudante A no período da tarde, duas vezes na semana, frequenta a SR para Deficiência Auditiva (DA) da própria escola, com a professora L, que possui graduação no curso de Pedagogia de Educação Especial pela Fundação Lusíada de Santos e também graduada em Enfermagem e Obstetrícia, além de possuir pós-graduação em enfermagem do trabalho e em Libras. Já atua no AEE há 20 anos. A Professora $L$ já trabalhou com a estudante $A$, quando a mesma tinha 7 e 8 anos de idade e no ano de 2015 novamente.

O primeiro contato com a E.E. João da Silva ocorreu por telefone, em que foi agendada uma conversa sobre a possibilidade do desenvolvimento do projeto de pesquisa aqui referido nas dependências da escola. Inicialmente o contato foi com a coordenadora pedagógica e foi agendado um horário para a proposta de realizar o projeto ser discutida.

No dia e horário preestabelecidos, foi realizada uma reunião com a coordenadora pedagógica e com o diretor da escola para explanar os objetivos do projeto e o cronograma das atividades propostas. Foi discutida também a importância desse trabalho para a escolarização dos estudantes surdos.

$\mathrm{Na}$ mesma oportunidade, conheci a estudante A. que, ao ter conhecimento sobre o projeto, mostrou-se muito interessada e aceitou participar do projeto. Após os acertos iniciais, foi estabelecido o cronograma de atividades. Todos os envolvidos no projeto mostraram-se muito interessados e dispostos em auxiliar na pesquisa.

As observações realizadas na classe comum do ensino regular e no APE aconteceram no mesmo período, pois assim, o pesquisador poderia ter um panorama geral da realidade escolar da estudante.

\footnotetext{
${ }^{4}$ Serão utilizadas siglas para identificação de todos os participantes da pesquisa a fim de preservar a identidade dos mesmos 
No período em que as observações foram realizadas, a professora $\mathrm{R}$ trabalhou o conteúdo sobre equações da reta, com todas suas variações e elementos que a compõem, como por exemplo, a determinação da equação da reta conhecendo um ponto e o coeficiente angular, pontos colineares e a equação geral e reduzida da reta.

A estudante A sempre esteve atenta as informações transmitidas pela professora interlocutora de Libras e nas explicações da professora de Matemática, apesar de não interagir muito com a professora. Observou-se que a Estudante $A$ também se comunica pouco com os demais estudantes e afirma que por não muitos não conhecerem o básico de Libras, fica difícil a comunicação entre ela e o restante da sala.

Também, durante uma das observações, foi feita uma avaliação sobre os assuntos citados, em que a estudante $A$ obteve um ótimo desempenho.

A estudante A afirma que gosta de Matemática e por ser uma disciplina visual, não tem grandes dificuldades, mas ressalta que vê este distanciamento entre a Matemática escolar e a realidade.

A professora L explicou que para o APE, é realizada no início do ano uma entrevista com os estudantes e pautados nessa entrevista e nos registros das atividades dos anos anteriores são elaborados um plano anual de trabalho e também planos bimestrais para melhor organização das atividades, visando atender as necessidades e potencialidades de cada estudante.

Durante as observações, o pesquisador observou a relação da estudante $A$ com os outros estudantes, com a professora de Matemática e com a professora interlocutora. Após cada observação, a sistematização do que foi observado pelo pesquisador no diário de campo foi essencial para que os dados e as características coletadas fossem todas armazenadas, pois Lüdke e André (1986) afirmam que analisar os dados qualitativos da pesquisa significa trabalhar todo o material coletado no decorrer da pesquisa.

A partir dos registros e das observações realizadas foi possível constatar que uma das preocupações da estudante é o futuro. Por ser estudante do 3o ano do Ensino Médio, preocupa-se com a inserção no mundo do trabalho e por gostar muito de fazer penteados, pensa em trabalhar em um salão de cabeleireiro. Portanto, verificou-se a necessidade de desenvolver atividades, mesmo que no ensino de Matemática, pautadas no contexto e nos interesses da estudante.

\section{DISCUSSÃO}

Diante do exposto, identificamos a importância do desenvolvimento de um trabalho pautado na utilização da resolução de problemas para a promoção de condições para a 
participação ativa dos estudantes surdos durantes as aulas e de um aprendizado efetivo dos conceitos matemáticos, pois "o que é aprendido só pode ser apropriado pelo sujeito se despertar nele certos ecos: se fizer sentido para ele." (CHARLOT, 2001, p.21)

O estabelecimento da relação entre a vida e o contexto do estudante e o conceito que será abordado é importante, pois os estudantes estão inseridos em um contexto social também possuem antecedentes geradores em campos de interesse. "A aprendizagem das diferentes disciplinas pode vir a ser realmente significativa se o aluno puder estabelecer relações entre as informações novas e os conceitos disponíveis em sua estrutura cognitiva" (PENA, apud AUSUBEL, 1999, p. 36).

É importante que o professor faça uso do cotidiano para estimular a participação de seus estudantes. Isso pode ser feito, de acordo com Carvalho (2007) mediante o trabalho com a resolução de problemas. Nessa perspectiva, os problemas que vão ser investigados pelos estudantes, não precisam necessariamente estar escritos nos cadernos e lousas, mas podem partir dos mais diversos contextos, promovendo mobilizações para a busca soluções para as perguntas que inquietam os estudantes.

\section{CONCLUSÃO}

Os resultados apresentados no presente artigo permitem verificar que é necessária a elaboração de atividades contextualizadas em sala de aula, que valorizem as diferenças de cada estudante, explorando suas habilidades e potencialidades. Buscando promover uma melhor participação da estudante A nas aulas de Matemática, observamos a importância da utilização de atividades que realmente sejam interessantes e estimuladoras, partindo da realidade dos estudantes e da escola.

O trabalho colaborativo entre a professora de Matemática e a professora da SR mostrou-se essencial, pois com a contribuição de cada uma, a aprendizagem de conceitos matemáticos pela estudante $A$, utilizando resolução de problemas poderá ser cada vez mais efetiva especialmente na compreensão da Matemática e sua importância para a sua formação e preparo para o mundo do trabalho.

\section{REFERÊNCIAS}

BRASIL. Ministério da Educação. Secretaria de Educação Especial. Diretrizes Nacionais para a Educação Especial na Educação Básica. Brasília: MEC/SEESP, 2001.

BRASIL. Lei no 10.436, de 24 de abril de 2002. Dispõe sobre a Língua Brasileira de Sinais - 
Libras e dá outras providências. Diário Oficial da União, Brasília, DF, 25 abr. 2002. Disponível em: http://www.planalto.gov.br/ccivil_03/leis/2002//10436.htm. Acesso em: 03 out. 2012a.

BRASIL. Decreto no 5.626, de 22 de dezembro de 2005. Regulamenta a Lei no 10.436, de 24 de abril de 2002, que dispõe sobre a Língua Brasileira de Sinais - Libras, e o art. 18 da Lei no 10.098, de 19 de dezembro de 2000. Diário Oficial da União, Brasília, DF, 23 dez. 2005. Disponível em: http://www.planalto.gov.br/ccivil_03/_ato2004-2006/2005/decreto/d5626.htm. Acesso em: 04 out. 2012c.

BRASIL. Resolução №. 4, de 2 de outubro de 2009. Institui as Diretrizes Operacionais para o Atendimento Educacional Especializado na Educação Básica, na modalidade Educação Especial. Conselho Nacional de Educação/Câmara de Educação Básica. Disponível em: <portal.mec.gov.br/dmdocuments/rceb004_09.pdf>. Acesso em: 04. jun. 2015.

CAPELLINI, V. L. M. F. Avaliação das possibilidades do ensino colaborativo no processo de inclusão escolar do aluno com deficiência mental. 2004. 300f. Tese (Doutorado em Educação Especial) - Programa de Pós-Graduação em Educação Especial: UFSCar, São Carlos, 2004.

CARVALHO, M. Problemas? Mas que problemas?!: estratégias de resolução de problemas matemáticos em sala de aula. Petrópolis: Vozes, 2007. 70 p.

CHARLOT, B. (Org.) Os jovens e o saber: perspectivas mundiais. Porto Alegre: Artmed, 2001. 152 p.

GIL, R. S. A. Educação Matemática dos Surdos: um estudo das necessidades formativas dos professores que ensinam conceitos matemáticos no contexto de educação de deficientes auditivos em Belém/PA. Dissertação (Mestrado em Ensino de Ciências e Matemática). Universidade do Pará. Belém, 2007.

LÜDKE, M; ANDRÉ, M. Pesquisa em Educação: Abordagens qualitativas. São Paulo: EPU, 1986.

MORAN COSTAS, J. M. Ensino e educação de qualidade (!?). In: Moran Costas, J. M.; MASETTO, M. T.; BEHTENS, M. A. Novas tecnologias e mediação pedagógica. 12. ed. Campinas: Papirus, 2006. p.12. Disponível em: <http://www3.eca.usp.br/prof/moram/qual.htm>. Acesso em: 06 de jun de 2015.

PENA, M. D. J. (1999). Formação continuada de professores na escola: O desafio da mudança, a partir da avaliação de aprendizagem. Tese de doutorado em Educação: Supervisão e Currículo. Pontifícia Universidade Católica de São Paulo.

POZO, J. I. (Org.). A solução de problemas: aprender a resolver, resolver para aprender. Porto Alegre: Artmed,1998. 177 p.

SALLES, H. M. M. L. Et.al. Ensino de Língua Portuguesa para surdos: caminhos para a prática pedagógica. Brasília: MEC, 2004, SEESP. V.1.

SECRETARIA DA EDUCAÇÃO DO ESTADO DE SÃO PAULO. Dispõe sobre a Educação Especial nas unidades escolares da rede estadual de ensino. Resolução n. 61, de 11 de novembro de 2014. DO: Diário Oficial, São Paulo. Legislação Estadual. Disponível em: 
<http://www.educacao.sp.gov.br/lise/sislegis/detresol.asp?strAto=201411110061>. Acesso em: 13 de jun de 2015. 